OPEN ACCESS

Edited by:

Louise Taylor,

Global Alliance for Rabies

Control, USA

Reviewed by:

Tenzin Tenzin,

National Centre for Animal

Health, Bhutan

Sarah Cleaveland,

University of Glasgow, UK

*Correspondence:

Helen Byrnes

helenbyrnes31@gmail.com

Specialty section:

This article was submitted to Veterinary Epidemiology and

Economics,

a section of the journal

Frontiers in Veterinary Science

Received: 31 October 2016

Accepted: 16 February 2017

Published: 15 March 2017

Citation:

Byrnes H, Britton A and Bhutia T (2017) Eliminating Dog-Mediated

Rabies in Sikkim, India: A 10-Year

Pathway to Success for the SARAH

Program.

Front. Vet. Sci. 4:28.

doi: $10.3389 /$ fvets. 2017.00028

\section{Eliminating Dog-Mediated Rabies in Sikkim, India: A 10-Year Pathway to Success for the SARAH Program}

\author{
Helen Byrnes ${ }^{1 *}$, Andrea Britton ${ }^{2}$ and Thinlay Bhutia ${ }^{3}$ \\ ${ }^{1}$ Vets Beyond Borders, Brisbane, QLD, Australia, ${ }^{2}$ Vets Beyond Borders, Melbourne, VIC, Australia, ${ }^{3}$ SARAH Division, \\ Department of Animal Husbandry, Livestock, Fisheries \& Animal Health, Government of Sikkim, Gangtok, India
}

A third of the world rabies burden is in India. The Sikkim Anti-Rabies and Animal Health (SARAH) program is the first state-wide rabies program in India and demonstrates a successful One Health model of dog-mediated rabies elimination. The SARAH program was created in 2006 as a collaboration between the Government of Sikkim and international non-government organizations - Vets Beyond Borders and Fondation Brigitte Bardot. Activities are directed to canine rabies vaccination, humane dog population control, community education, and treatment of sick and injured animals. In 2005, there were 0.74 human rabies deaths per 100,000 (4 deaths) within Sikkim, and from 2006 to 2015, there were no human rabies deaths. In 2016, two human rabies deaths were reported near the West Bengal border region. From 2005 to 2010, the incidence of animal rabies is unknown; from 2010 to 2016, eight cases of animal rabies were reported. Major challenges for the program are continued commitment to rabies control in the face of 0 to low human rabies incidence and the risk of rabies incursions. Effective intersectoral communication between Health, Veterinary, Forestry, and Police officers is essential to enable rapid response to animal bite incidents and possible rabies incursions. An integrated One Health approach needs to be maintained with enhanced active rabies surveillance. Other states must establish similar programs if India is ever to achieve a goal of eliminating dog-mediated human rabies.

Keywords: SARAH program, Sikkim India, rabies elimination, One Health, mass dog vaccination, dog population management, animal welfare, surveillance

\section{INTRODUCTION}

Globally, the incidence of human rabies deaths transmitted from dogs is estimated at 59,000 people, and a third of the world rabies burden is in India $(1,2)$. In India, there is no national strategy for the elimination of rabies (1), and rabies is not a notifiable disease. Recently, pilot programs for rabies control have commenced in the states of Tamil Nadu and Haryana (3-5), and a number of animal-welfare groups throughout the country include canine rabies vaccination in their activities. The state of Sikkim has implemented a state-wide One Health rabies program since 2006. Sikkim is a small Himalayan state in North East India bordered by Nepal, China, and Bhutan (Figure 1), with a population of 610,000 (2011 census) (6). The core components of the Sikkim Anti-Rabies and Animal Health (SARAH) program (the Program) are canine rabies vaccination, dog population management, and rabies prevention education, which have been shown to control and prevent 


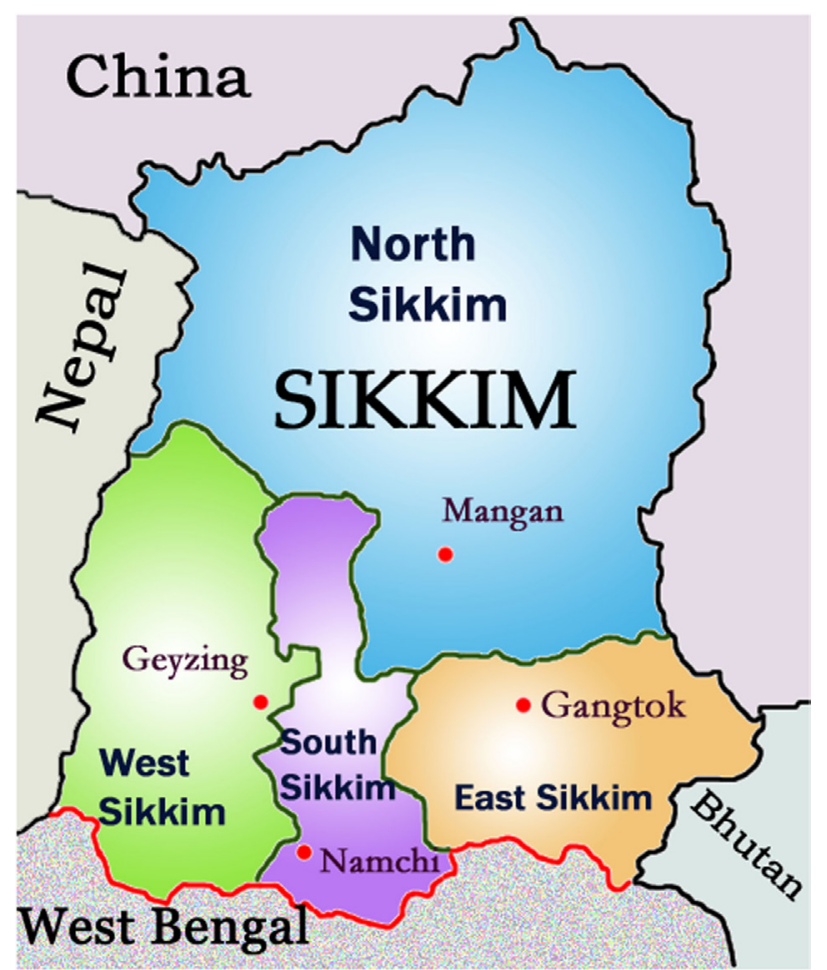

FIGURE 1 | Map of Sikkim, India-rabies incursions occurred near border of South and West Sikkim and West Bengal border.

rabies leading to elimination $(7,8)$. It also provides health care to street dogs and aims to foster a compassionate attitude toward all animals. The Program enjoys strong community support within Sikkim for its efforts in rabies control and improvements in animal welfare.

The SARAH program was created as a collaboration between the Government of Sikkim, Australian non-government organization (NGO) - Vets Beyond Borders (VBB), and French $\mathrm{NGO}-$ Fondation Brigitte Bardot (FBB) in response to the public of Sikkim requesting that mass shooting of street dogs cease and a more humane method of controlling the dogs be implemented. In 2005, human rabies incidence in Sikkim was 0.74 deaths per 100,000 persons, totaling 4 human deaths (Table 1). From 2006, there were no reported cases of human rabies until 2016. Two animal cases were reported in 2010; no further animal cases were reported until 2015. Data for reports of animal rabies cases are poor prior to 2010 .

This paper provides a perspective on the implementation of the SARAH program for the control and elimination of dogmediated human rabies in Sikkim and the benefits and challenges of a One Health approach $(7,9,10)$.

\section{DOG KEEPING IN SIKKIM}

Sikkim is largely rural, with $47 \%$ of the state under forest cover. Seventy-five percent of the state's population reside in rural areas. The main urban center is Gangtok (Figure 1) with 100,000 people. Sikkim is a multiethnic state with strong influences of Buddhism (the state religion until Sikkim became an Indian state in 1975) and Nepalese Hindu. The majority of the population is Nepalese (11), and Nepali is the most common language spoken (12).

Dogs in Sikkim are traditionally kept outside as protectors against wildlife intrusion such as Himalayan bear, but also against bad spirits and adverse life events $(13,14)$. With increased standard of living most village households now keep one or more dogs. In villages, young puppies are often kept inside, and when older are kept outside and handled little. In urban areas, there is an increasing incidence of western-style pet ownership with dogs living inside as members of the family. Workers brought into Sikkim for contract jobs associated with construction of hydroelectric plants usually keep three to four dogs per household. These dogs are kept outside, free roaming and are often difficult to handle. When the contract is finished, the workers move away and usually leave the dogs on the street.

Free roaming dogs are common in Sikkim, and the supervision and responsibility felt for these dogs is on a continuum from nothing to full responsibility. Many family owned dogs are allowed to roam freely. A culture of quasi-ownership has been described in the city of Ranchi, India (15) where people feed roaming dogs but do not take responsibility for vaccination or sterilization, and dog catching with butterfly nets is required for vaccinating these dogs. Over the lifetime of the SARAH program, use of butterfly nets has reduced, and most dogs can now be caught by hand by the SARAH team or community members. While $42 \%$ of dogs were reported as stray in Tamil Nadu (5), on average in Sikkim 18\% of the total dog population are unsupervised dogs for which no one takes responsibility and which require capture with butterfly nets. In South Sikkim where there are many contract workers, the unsupervised roaming dog population is $27 \%$ (Table 2 ).

There is also a population of feral dogs in the forests in the China border regions, which is likely to be derived from abandoned puppies from army camp dogs. Efforts are made to vaccinate and surgically sterilize these dogs in a trap and release program. The army has permitted access to army camps for the surgical sterilization and rabies vaccination of camp dogs to enable a buffer zone of vaccinated neutered dogs. The army has cooperated with improved garbage control in army camps thus eliminating a food source for feral dogs.

\section{COMMUNITY ENGAGEMENT}

Sikkim Anti-Rabies and Animal Health community education on rabies prevention have been designed around core Buddhist and Nepali Hindu religious beliefs including animal sentience, the cherished relationship between people and dogs, and the role of dogs in providing security, and their loyalty and friendship. The Program recognizes that human-animal relationships are "economic, cultural, and emotional in nature" $(16,17)$ and that dog keeping practices and norms of responsible pet ownership vary in different localities and cultures and can change over time. Animal-welfare lessons were incorporated into early school syllabus in 2009, and further lessons will be incorporated in the 2018 syllabus. The Program has been very careful to address the felt needs of the community to generate community participation. 
TABLE 1 | Program data on activities and incidence of dog bites and rabies cases, program funding, and volunteers.

\begin{tabular}{|c|c|c|c|c|c|c|c|c|c|c|}
\hline Year & $\begin{array}{l}\text { Rabies } \\
\text { vaccine } \\
\text { doses } \\
\text { given }\end{array}$ & $\begin{array}{l}\text { Nos. surgical } \\
\text { sterilizations }\end{array}$ & $\begin{array}{l}\text { No. of sick/ } \\
\text { injured } \\
\text { animals } \\
\text { treated }\end{array}$ & $\begin{array}{c}\text { No. of public } \\
\text { awareness } \\
\text { events }\end{array}$ & $\begin{array}{l}\text { Dog bite } \\
\text { incidents }\end{array}$ & $\begin{array}{l}\text { Suspect } \\
\text { human } \\
\text { rabies } \\
\text { cases } \\
\text { reported }\end{array}$ & $\begin{array}{l}\text { Suspect } \\
\text { animal } \\
\text { rabies } \\
\text { cases } \\
\text { reported }\end{array}$ & $\begin{array}{l}\text { Fondation } \\
\text { Brigitte } \\
\text { Bardot } \\
\text { funding } \\
\text { (Euro) }\end{array}$ & $\begin{array}{l}\text { Government of } \\
\text { Sikkim funding } \\
\text { (Euro) }\end{array}$ & $\begin{array}{c}\text { Vets Beyond } \\
\text { Borders } \\
\text { volunteers } \\
\text { (weeks) }\end{array}$ \\
\hline 2003 & 0 & 0 & $\mathrm{n} / \mathrm{a}$ & $\mathrm{n} / \mathrm{a}$ & $\mathrm{n} / \mathrm{a}$ & 1 & $\mathrm{n} / \mathrm{a}$ & 0 & 0 & 0 \\
\hline 2004 & 0 & 0 & $\mathrm{n} / \mathrm{a}$ & $\mathrm{n} / \mathrm{a}$ & $\mathrm{n} / \mathrm{a}$ & 2 & $\mathrm{n} / \mathrm{a}$ & 0 & 0 & 0 \\
\hline $2005 / 2006$ & 1,400 & 830 & $\mathrm{n} / \mathrm{a}$ & $\mathrm{n} / \mathrm{a}$ & 853 & 4 & $\mathrm{n} / \mathrm{a}$ & 12,410 & 0 & 81 \\
\hline 2006/2007 & 7,006 & 4,942 & $\mathrm{n} / \mathrm{a}$ & $\mathrm{n} / \mathrm{a}$ & $\mathrm{n} / \mathrm{a}$ & 0 & $\mathrm{n} / \mathrm{a}$ & 109,000 & 70,000 & 103 \\
\hline $2007 / 2008$ & 8,514 & 5,618 & $\mathrm{n} / \mathrm{a}$ & $\mathrm{n} / \mathrm{a}$ & $\mathrm{n} / \mathrm{a}$ & 0 & 0 & 63,981 & 57,400 & 115 \\
\hline 2008/2009 & 7,523 & 4,364 & $\mathrm{n} / \mathrm{a}$ & $\mathrm{n} / \mathrm{a}$ & 2,320 & 0 & 0 & 70,000 & 58,212 & 111 \\
\hline 2009/2010 & 4,941 & 2,797 & $\mathrm{n} / \mathrm{a}$ & $\mathrm{n} / \mathrm{a}$ & 1,082 & 0 & 0 & 23,000 & 71,400 & 79 \\
\hline 2010/2011 & 16,807 & 3,283 & 611 & $\mathrm{n} / \mathrm{a}$ & 1,334 & 0 & 2 & 21,600 & 28,000 & 42 \\
\hline $2011 / 2012$ & 18,611 & 4,060 & 1,123 & $\mathrm{n} / \mathrm{a}$ & 1,348 & 0 & 0 & 20,500 & 74,200 & 47 \\
\hline $2012 / 2013$ & 17,466 & 2,947 & 1,581 & 72 & 3,315 & 0 & 0 & 14,500 & 74,900 & 92 \\
\hline $2013 / 2014$ & 23,669 & 4,289 & 2,245 & 120 & $\mathrm{n} / \mathrm{a}$ & 0 & 0 & 13,000 & 61,600 & 39 \\
\hline $2014 / 2015$ & 23,706 & 4,300 & 1,925 & 86 & $\mathrm{n} / \mathrm{a}$ & 0 & 4 & 18,000 & 21,000 & 39 \\
\hline $2015 / 2016$ & 24,571 & 5,487 & 2,304 & 190 & $\mathrm{n} / \mathrm{a}$ & 2 & 2 & 22,976 & 62,300 & 40 \\
\hline
\end{tabular}

n/a, not available. Dog bite data provided by Sikkim Department of Health include potential rabies exposure associated with animals such as drinking milk from a cow bitten by a dog or jackal.

TABLE 2 | Estimated number of dogs and canine rabies vaccination in four districts of Sikkim.

\begin{tabular}{|c|c|c|c|c|c|c|c|c|}
\hline \multirow[t]{2}{*}{ Year } & $\begin{array}{c}\text { Number dogs } \\
\text { vaccinated }\end{array}$ & $\begin{array}{c}\text { Dog } \\
\text { population }\end{array}$ & $\begin{array}{c}\text { Number dogs } \\
\text { vaccinated }\end{array}$ & $\begin{array}{c}\text { Dog } \\
\text { population }\end{array}$ & $\begin{array}{c}\text { Number dogs } \\
\text { vaccinated }\end{array}$ & $\begin{array}{c}\text { Dog } \\
\text { Population }\end{array}$ & $\begin{array}{c}\text { Number dogs } \\
\text { vaccinated }\end{array}$ & $\begin{array}{c}\text { Dog } \\
\text { population }\end{array}$ \\
\hline & East (\% vac East) & East & $\begin{array}{c}\text { South (\% vac } \\
\text { South) }\end{array}$ & South & $\begin{array}{c}\text { North (\% vac } \\
\text { North) }\end{array}$ & North & $\begin{array}{c}\text { West (\% vac } \\
\text { West) }\end{array}$ & West \\
\hline 2011 & $9,567(50)$ & 19,000 & $3,108(31)$ & 10,000 & $1,286(32)$ & 4,000 & $2,846(36)$ & 8,000 \\
\hline 2012 & $12,504(69)$ & 18,200 & $2,931(32)$ & 9,200 & $635(16)$ & 4,000 & $2,541(35)$ & 7,200 \\
\hline 2013 & 12,848 (69) & 18,500 & $2,341(25)$ & 9,500 & $598(15)$ & 4,000 & 1,679 (22) & 7,500 \\
\hline 2014 & $14,458(76)$ & 19,000 & $4,932(49)$ & 10,000 & $828(21)$ & 4,000 & $3,451(43)$ & 8,000 \\
\hline 2015 & $14,927(83)$ & 18,000 & $4,720(45)$ & 10,500 & $1,037(26)$ & 4,000 & $3,022(36)$ & 8,500 \\
\hline 2016 & $14,361(85)$ & 17,000 & $5,916(54)$ & 11,000 & $733(18)$ & 4,000 & $3,561(40)$ & 9,000 \\
\hline
\end{tabular}

Vaccination coverage is based on dog population size estimates provided by village councils and Department of Animal Husbandry field officers. Feral dogs in forests are excluded from the data estimates.

As trust in the Program has developed, the community is more aware of rabies, and societal norms of animal welfare have changed. Community members will now bring dogs for vaccination and sterilization or describe where they can be found enabling many of the unsupervised dogs to be vaccinated and sterilized. Family planning in women in Sikkim has been actively promoted by the Government (18), and the potential benefits of "family planning" in dogs in reducing the number of unwanted puppies and associated animal-welfare problems were quickly recognized by the community; the community reports fewer dog fights particularly during the breeding season. An increase in dog bite incident reports is seen twice yearly in dog breeding season (March/April and September/October), during the major festival in September/October and following rabies education activities.

Community participation and cooperation is integral to the Program. Key messages to encourage participation are (1) canine rabies vaccination is needed for control of human rabies, (2) surgical desexing will reduce dog roaming and fighting, and hence the risk of rabies, (3) canine rabies vaccination and sterilization are provided free of charge, (4) sterilization will reduce the number of unwanted puppies, and (5) if your dog is unvaccinated and bites a person, you may be held responsible by the Panchayat (local village council) and the affected person for the cost of PEP for the affected person. PEP is available free from public hospitals, but if it is unavailable at the hospital, it must be purchased from a private medical store. In the last 2 years, Panchayats have placed the onus of financial responsibility for PEP on the owners of unvaccinated dogs.

\section{STAGES OF DEVELOPMENT}

The SARAH program has developed over 10 years with capacity building and government commitment from a small NGO-managed program relying substantially on international volunteers to a state-wide government program, providing a One Health model of sustainable dog-mediated rabies elimination. 


\section{INITIAL STAGE}

Initially, Program administration, veterinary volunteers, and training were delivered through VBB with a VBB Program manager present in Sikkim and 2-3 international volunteers assisting with the work throughout the year. FBB provided funding on a matching grant arrangement with the Government of Sikkim with the expectation that after 3 years the project would be taken over by the government. Government provided facilities for clinics and public education, accommodation for volunteers, and local staff for the project. A SARAH clinic was established for surgical sterilization, rabies vaccination, and treatment of sick and injured street dogs; mobile units enabled the Program to be extended to rural regions.

Initial and subsequent training activities had a strong emphasis on animal welfare and have been critical for community acceptance of the Program and cost control. Extensive training of local veterinarians in veterinary surgery and medicine, and local staff in animal handling and dog catching occurred through the formal VBB VetTrain@ program. Volunteers provided mentoring, on-the-job training, and train-the-trainer programs to local staff. Important elements for community support for the Program were the adoption of humane catching methods, which cause minimal distress to animals and demonstrate a recognition of animal sentience and the significance of dogs in the community, good surgical outcomes with a low rate of surgical complications $(<0.003 \%)$, rapid return of dogs to their home territory (within $24 \mathrm{~h}$ for healthy dogs), and commitment to treat all sick/injured street dogs.

In 2009, the Program became a Division of the Department of Animal Husbandry. VBB volunteers continued to participate, but VBB had a reduced role in Program administration; FBB provided reducing financial support (Table 1).

\section{INTERMEDIATE STAGE}

Multisectoral cooperation is essential for sustained rabies elimination (19), accordingly, a seminar on rabies and emerging zoonotic diseases was held in 2009. Representatives from the government veterinary and medical fraternity of the State Government were invited; few medical personnel attended. There were two major outcomes from the meeting. The first was the establishment of the Wildlife Conservation and Feral Dog Program to prevent the spread of wildlife rabies into the dog population in Sikkim by creating a buffer zone of rabies vaccinated dogs in the border regions adjacent to China and Nepal.

The second decision was to implement an annual state-wide rabies vaccination campaign each September with World Rabies Day activities incorporated (pet shows, school activities, and media releases). Critically, the implementation of state-wide rabies vaccination extended the Program to the rural regions of Sikkim. Canine rabies vaccine is provided free of charge; annual rabies vaccination of pet dogs is compulsory under state legislation. Houseto-house vaccination was needed initially, but central vaccination posts are now feasible in most villages. A catch-vaccinate-releaseresight program is undertaken for street dogs with marking of vaccinated dogs with paint. An annual dog census is correlated with village council knowledge of dog numbers facilitating $70 \%$ vaccination coverage to be achieved in East Sikkim (20-22). Vaccination coverage by district is shown in Table 2.

A distemper outbreak occurred in 2012 resulting in the death of thousands of dogs and community fear that distemper was caused by rabies vaccine. Extensive community education was undertaken to ensure participation in subsequent rabies vaccination campaigns and encourage owners to vaccinate dogs for distemper.

A One Health Intersectoral Rabies Committee was established in 2012 to transcend sectoral boundaries, comprised of Departments of Health, Animal Husbandry, Forestry, Urban Housing \& Development, Police, and Army. The tasks of the committee were to prepare a proposal for rabies to be a notifiable disease in Sikkim, formulate procedures for restrictions of crossborder dog movement, formulate procedures for dog registration, work with the National Centre for Disease Control to establish a State Surveillance Laboratory for rabies control, develop a surveillance system for achieving rabies, and improve garbage control. A major achievement was rabies becoming a notifiable disease in Sikkim in 2014 for animals and humans (23). Garbage management has improved with daily rubbish collection in major towns, and weekly rubbish collection in regional districts.

\section{CURRENT STAGE AND ONE HEALTH OUTBREAK RESPONSES}

Both human and canine rabies were controlled in Sikkim during 2006-2015. Complacency developed about rabies as the perception of disease risk was low. The Health Department stopped stocking PEP and rabies immunoglobulin (RIG), and the need for rabies surveillance and development of laboratory capacity was given low priority. This occurred in the face of complex ecological interactions including wildlife habitat disruption associated with road construction, socioeconomic change, and a migratory workforce located in Sikkim who bring unvaccinated dogs with them and are on the fringe of Sikkim civil society.

In December 2014, two people and a number of dogs were bitten by a jackal in a village close to the West Bengal border. Dog brain samples were sent interstate for testing, but the results were inconclusive. In February 2016, there were reports of a jackal attacking cows near the West Bengal border. Two cows tested positive for rabies (Table 1). Subsequently, two suspect human rabies deaths were reported in a nearby village. One person had been bitten by an unvaccinated pet dog, refused medical treatment, and died. The other person had no history of dog bite and died in hospital. Laboratory confirmation was not undertaken reflecting problems previously identified in effective surveillance of rabies programs (24): inadequate training in sample collection, difficulties in getting samples to a diagnostic laboratory from Sikkim, and family reluctance to allow postmortem diagnosis.

\section{DISCUSSION}

\section{Vaccination and Dog Population Control}

Rabies vaccination of dogs is the cornerstone of rabies control $(25,26)$. The logistics of a state-wide vaccination campaign in the Himalayas are difficult. Cooperation of villagers, Panchayats, 
and Department of Animal Husbandry field officers is essential. Human-mediated dog movement and gaps in coverage are problems in effective rabies programs (27). Recent rabies incursions in South Sikkim occurred in areas where there is human-mediated dog movement, where they have been gaps in vaccine coverage (Table 2), and which is adjacent to West Bengal with no rabies program. A Program team is now permanently located in South Sikkim to improve vaccination coverage and dog population management.

Dog population management is important for the Program goals of improved animal welfare $(28,29)$ and rabies control; the numbers of dogs sterilized annually are approximately $20 \%$ of the dogs vaccinated in Sikkim each year (Table 1). It is also important because it addresses community concerns about dog fighting and nuisance, and unwanted puppies. Improved animal welfare supports a more stable dog population. Community assistance with dog catching enables a minimal although highly skilled dog catching team. The aides who assist with surgery are also the dog-catching team. This has enabled control of a major cost, for the size of the dog catching team can be a significant cost in a dog population management program (3).

\section{Intersectoral Coordination, Community Engagement, and Animal Welfare}

Intersectoral coordination and communication, essential for rabies control $(10,19)$, is an ongoing challenge. The establishment of a One Health Intersectoral Committee provided the authority for SARAH to seek cooperation at district and village level. The perceived success in controlling rabies and dog population management together with wide community support facilitated cooperation at all levels, although an unanticipated outcome was the Department of Health's interim decision to stop stocking PEP and RIG.

Education on animal welfare and the obligation to care and value dogs has been associated with increased community participation and support for the Program. There is a temptation to assume that the animal welfare emphasis of the Program will only work in Sikkim where animal sentience is accepted and the complex relationship between people and dogs is acknowledged in festivals such as Tihar (Deepawali). It has been suggested that the important role of dogs in Hinduism may be an impediment for successful program adoption (30), but in Sikkim, it has facilitated program adoption. An increase in empathy and improved attitudes to animals has been shown to increase empathy to humans and facilitate prosocial behavior (31-36), which may in turn motivate health behaviors including participation in vaccination campaigns (28). A critical feature in the SARAH program is the recognition of the significance of human-animal relations and culturally appropriate framing of community education messages.

\section{Challenges Facing the SARAH Program}

Recent suspect rabies cases highlighted the need for formal and regular intersectoral communication at community level, the need for improved epidemiological data, for enhanced active surveillance related to animal bites, training for appropriate medical response to suspect rabies dog bite, the logistical difficulties in getting both human and animal samples from Sikkim to a laboratory for confirmation of rabies, and the ongoing risk of rabies incursion and sylvatic rabies.

The seasonal pattern of the recent rabies outbreaks occurring at the border during winter when food sources are scarce suggests rabies incursions into Sikkim, rather than ongoing circulation of rabies within Sikkim. An effective surveillance system with tracing back of suspect animals is needed to confirm this hypothesis $(37,38)$. Increasing human wildlife conflict in Sikkim (6) may increase the risk of rabies transmission. If rabies were controlled in domestic dogs in surrounding areas, it is not known if jackal could sustain the circulation of rabies although Lembo (20) concluded that dogs were the only species essential for rabies persistence in the Serengeti. There are clear limitations in the accuracy of vaccination coverage estimates based on dog population size estimates provided by village council knowledge. However, the data suggest that vaccination coverages of $70 \%$ are likely to be feasible in Sikkim, as shown by consistently high estimates achieved in East Sikkim.

The SARAH program is a State Government supported program and lacks the international resources available to national programs. Effort is being directed at establishing low cost enhanced active rabies surveillance (37). The Rapid Test (BioNote) is used in the field when available. Discussions are being held with counterparts in West Bengal for extension of the rabies program into West Bengal, but resources are limited for both parties.

\section{CONCLUSION}

The Sikkim Government, together with SARAH partner NGO$\mathrm{VBB}$ and $\mathrm{FBB}$, has made a considerable investment to eliminate dog-mediated rabies. The recent re-emergence of rabies in Sikkim highlights the imperative of an integrated One Health approach to increase the sensitivity of rabies surveillance and to ensure interruption of rabies transmission. The SARAH program is a model of rabies control in a predominantly rural environment with limited resources. It is also an example of the challenges encountered in maintaining rabies control in a landlocked state. Other Indian states must establish similar programs if India is ever to achieve a goal of eliminating dog-mediated human rabies.

\section{AUTHOR CONTRIBUTIONS}

HB has been involved in the SARAH program since 2006. HB and $\mathrm{AB}$ researched, designed, and wrote this paper. $\mathrm{TB}$ has been local coordinator for the program since inception and provided expert and local knowledge about the paper subject.

\section{FUNDING}

The Sikkim Anti-Rabies and Animal Health program is funded by the Government of Sikkim, India and Fondation Brigitte Bardot, France. The authors would like to thank the tireless efforts of the many volunteers from Vets Beyond Borders, Australia, who have worked in the program. 


\section{REFERENCES}

1. Fahrion AS, Mikhailov A, Abela-Ridder B, Giacinti J, Harries J. Human rabies transmitted by dogs: current status of global data, 2015. Wkly Epidemiol Rec (2016) 91(2):13-20.

2. Hampson K, Coudeville L, Lembo T, Sambo M, Kieffer A, Attlan M, et al. Estimating the global burden of endemic canine rabies. PLoS Negl Trop Dis (2015) 9(4):e0003709. doi:10.1371/journal.pntd.0003709

3. Abbas SS, Kakkar M, Rogawski ET. On behalf of the roadmap to combat zoonoses in India. I. Costs analysis of a population level rabies control programme in Tamil Nadu, India. PLoS Negl Trop Dis (2014) 8(2):e2721. doi:10.1371/ journal.pntd.0002721

4. National Rabies Control Program National Health Portal India. (2017). Available from: http://117.239.178.13/national-rabies-control-programme

5. Fitzpatrick MC, Shah HA, Pandey A, Bilinski AM, Kakkar M, Clark AD, et al. One health approach to cost-effective rabies control in India. Proc Natl Acad Sci U S A (2016) 113(51):14574-81. doi:10.1073/pnas.1604975113

6. Sikkim Human Development Report 2014. New Delhi: Routledge (2014).

7. Cleaveland S, Beyer H, Hampson K, Haydon D, Lankester F, Lembo T, et al. The changing landscape of rabies epidemiology and control. Onderstepoort $J$ Vet Res (2014) 81(2):2014. doi:10.4102/ojvr.v81i2.731

8. Knobel DL, Lembo T, Morters M, Townsend SE, Cleaveland S, Hampson K. Chapter 17 - Dog Rabies and Its Control A2 - Jackson, Alan C. Rabies. Third ed. Boston: Academic Press (2013). p. 591-615.

9. Lechenne MMM, Zinsstag J. Integrated rabies control. In: Zinsstag JSE, Waltner-Toews D, Whittaker M, Tanner M, editors. One Health: The Theory and Practice of Integrated Health Approaches. CAB International (2015). p. 176-89.

10. Cleaveland S, Lankester F, Townsend S, Lembo T, Hampson K. Rabies control and elimination: a test case for one health. Vet Rec (2014) 175(8):188-93. doi:10.1136/vr.g4996

11. Demographic Features: Home Department, Government of Sikkim. Available from: http://sikkim.nic.in/homedept/demog.htm (accessed October 31, 2016; February 21, 2017).

12. Sikkim in Brief. Gangtok: Department of Economics, Statistics, Monitoring \& Evaluation, Government of Sikkim (2005).

13. Ekvall R. The role of the dog in Tibetan nomadic society. Cent Asiatic J (1963) VIII:163-73.

14. Vargas I. Snake-kings, boars' heads, deer parks, monkey talk: animals as transmitters and transformers in Indian and Tibetan Buddhist narratives. In: Waldau P, Patton K, editors. A Communion of Subjects: Animals in Religion, Science, and Ethics. USA: Columbia University Press (2006). p. 217-37.

15. Gibson AD, Ohal P, Shervell K, Handel IG, Bronsvoort BM, Mellanby RJ, et al. Vaccinate-assess-move method of mass canine rabies vaccination utilising mobile technology data collection in Ranchi, India. BMC Infect Dis (2015) 15:589. doi:10.1186/s12879-015-1320-2

16. Rock M, Buntain BJ, Hatfield JM, Hallgrimsson B. Animal-human connections, "one health," and the syndemic approach to prevention. Soc Sci Med (2009) 68(6):991-5. doi:10.1016/j.socscimed.2008.12.047

17. Porter N. Bird flu biopower: strategies for multispecies coexistence in Việt Nam. Am Ethnol (2013) 40(1):132-48. doi:10.1111/amet.12010

18. Sciences IIfP. District Level Household and Facility Survey (DLHS-4), 2012-13: India. Sikkim. Mumbai: International Institute for Population Sciences (2014).

19. Lapiz SM, Miranda ME, Garcia RG, Daguro LI, Paman MD, Madrinan FP, et al. Implementation of an intersectoral program to eliminate human and canine rabies: the Bohol rabies prevention and elimination project. PLoS Negl Trop Dis (2012) 6(12):e1891. doi:10.1371/journal.pntd.0001891

20. Lembo T, Hampson K, Kaare MT, Ernest E, Knobel D, Kazwala RR, et al. The feasibility of canine rabies elimination in Africa: dispelling doubts with data. PLoS Negl Trop Dis (2010) 4(2):e626. doi:10.1371/journal.pntd.0000626

21. Coleman PG, Dye C. Immunization coverage required to prevent outbreaks of dog rabies. Vaccine (1996) 14(3):185-6. doi:10.1016/0264-410X(95)00197-9

22. Hampson K, Dushoff J, Cleaveland S, Haydon DT, Kaare M, Packer C, et al. Transmission dynamics and prospects for the elimination of canine rabies. PLoS Biol (2009) 7(3):e1000053. doi:10.1371/journal.pbio.1000053
23. Sikkim Government Gazette, No. 554. Sect. No. 27/AHぬVS Adm. (2014).

24. Taylor LH, Hampson K, Fahrion A, Abela-Ridder B, Nel LH. Difficulties in estimating the human burden of canine rabies. Acta Trop (2017) 165:133-40. doi:10.1016/j.actatropica.2015.12.007

25. Betsch C, Böhm R, Chapman GB. Using behavioral insights to increase vaccination policy effectiveness. Policy Insights Behav Brain Sci (2015) 2(1):61-73. doi:10.1177/2372732215600716

26. Wa OIE. Global Elimination of Dog-Mediated Human Rabies - The Time Is Now. Report of the Rabies Global Conference, 10-11 December 2015. Geneva, Switzerland. Available from: http://apps.who.int/iris/ bitstream/10665/204621/1/WHO_HTM_NTD_NZD_2016.02_eng. pdf?ua=12016 (accessed November 2, 2016).

27. Townsend SE, Sumantra IP, Pudjiatmoko, Bagus GN, Brum E, Cleaveland S, et al. Designing programs for eliminating canine rabies from islands: Bali, Indonesia as a case study. PLoS Negl Trop Dis (2013) 7(8):e2372. doi:10.1371/ journal.pntd.0002372

28. International Companion Animal Management Coalition. Are We Making a Difference: A Guide to Monitoring and Evaluating Dog Population Management Interventions. International Companion Animal Management Coalition (2015). Available from: http://www.icam-coalition.org/downloads/ ICAM_Guidance_Document.pdf (accessed August 15, 2016).

29. Yoak AJ, Reece JF, Gehrt SD, Hamilton IM. Disease control through fertility control: secondary benefits of animal birth control in Indian street dogs. Prev Vet Med (2014) 113(1):152-6. doi:10.1016/j.prevetmed.2013.09.005

30. Devleesschauwer B, Aryal A, Sharma BK, Ale A, Declercq A, Depraz S, et al. Epidemiology, impact and control of rabies in Nepal: a systematic review. PLoS Negl Trop Dis (2016) 10(2):e0004461. doi:10.1371/journal.pntd.0004461

31. Ascione FR, Weber CV. Children's attitudes about the humane treatment of animals and empathy: one-year follow up of a school-based intervention. Anthrozoos (1996) 9(4):188-95. doi:10.2752/089279396787001455

32. Hergovich A, Monshi B, Semmler G, Zieglmayer V. The effects of the presence of a dog in the classroom. Anthrozoos (2002) 15(1):37-50. doi:10.2752/089279302786992775

33. Tissen I, Hergovich A, Spiel C. School-based social training with and without dogs: evaluation of their effectiveness. Anthrozoos (2007) 20(4):365-73. doi:10.2752/089279307X245491

34. Sprinkle JE. Animals, empathy, and violence can animals be used to convey principles of prosocial behavior to children? Youth Violence Juvenile Justice (2008) 6(1):47-58. doi:10.1177/1541204007305525

35. Zasloff RL, Hart LA, Weiss JM. Dog training as a violence prevention tool for at-risk adolescents. Anthrozoos (2003) 16(4):352-9. doi:10.2752/089279303786992044

36. Arkow P. The impact of companion animals on social capital and community violence: setting research, policy and program agendas. J Sociol Soc Welf (2013) 40(4):33-56.

37. Wallace RM, Reses H, Franka R, Dilius P, Fenelon N, Orciari L, et al. Establishment of a canine rabies burden in Haiti through the implementation of a novel surveillance program. PLoS Negl Trop Dis (2015) 9(11):e0004245. doi:10.1371/journal.pntd.0004245

38. Banyard AC, Horton DL, Freuling C, Muller T, Fooks AR. Control and prevention of canine rabies: the need for building laboratory-based surveillance capacity. Antiviral Res (2013) 98(3):357-64. doi:10.1016/j. antiviral.2013.04.004

Conflict of Interest Statement: The authors declare that the research was conducted in the absence of any commercial or financial relationships that could be construed as a potential conflict of interest.

Copyright (c) 2017 Byrnes, Britton and Bhutia. This is an open-access article distributed under the terms of the Creative Commons Attribution License (CC BY). The use, distribution or reproduction in other forums is permitted, provided the original author(s) or licensor are credited and that the original publication in this journal is cited, in accordance with accepted academic practice. No use, distribution or reproduction is permitted which does not comply with these terms. 